\title{
OLIMPÍADAS DE CIÊNCIAS: UMA PRÁTICA EM QUESTÃO
}

\section{Science olympiads: a practice in question}

\author{
Flávia Rezende ${ }^{1}$ Fernanda Ostermann ${ }^{2}$
}

Resumo: Neste trabalho questionamos a prática das olimpíadas escolares como uma das medidas de Estado que, pretensamente, visam à melhoria do ensino nas escolas públicas e, mais fortemente, as olimpíadas das ciências naturais, área de conhecimentos historicamente excludente. Com base na perspectiva histórico-cultural sobre aprendizagem, argumentamos contra a competitividade e a favor da colaboração nos processos educativos. A partir de análises da desigualdade escolar balizadas pela sociologia da educação, colocamo-nos contra a competição injusta entre estudantes já pré-selecionados por seu capital cultural. Defendemos que a interação, a colaboração e a democracia são valores defensáveis tanto do ponto de vista cognitivo ou educativo quanto do ponto de vista da formação humana. Concluímos sobre a necessidade de se investir em políticas que não sirvam apenas como tapa-buraco das condições ainda precárias da escola pública brasileira e que fomentem valores que possam produzir transformações na sociedade desigual em que vivemos.

Palavras-chave: Ensino de Ciências. Olimpíada escolar. Política educacional. Competitividade.

\begin{abstract}
In this work we question the scholarly olympiads as one of the government policies that, at a first glance, intend to improve the teaching in public schools and, with more emphasis, the olympiads in natural science, a historically excluded knowledge field. Based on the historical-cultural perspective of learning, we argue against competitiveness and for cooperation and democracy in the educational processes. From an analysis of scholar inequality directed by the sociology of education, our position is against unfair competition among students pre-selected by their cultural background. We argue that interaction, collaboration and democracy are relevant values both from cognitive or humanist points of view. We conclude with the need to invest in policies that do not serve only as a stopgap to the still precarious conditions of the Brazilian public schools but to promote other values which can produce changes in the unequal society that we live in.
\end{abstract}

Keywords: Science teaching. School Olympiad. Educational policy. Competitivity.

\footnotetext{
${ }^{1}$ Núcleo de Tecnologia Educacional para a Saúde, Universidade Federal do Rio de Janeiro. Ed. Centro de Ciências da Saúde, Bloco A - Sala 12, Cidade Universitária. Rio de Janeiro, RJ, Brasil. 21.941-902. flaviarezende@uol.com.br

${ }^{2}$ Instituto de Física, Universidade Federal do Rio Grande do Sul.
} 


\section{Problematização}

Historicamente, o ensino de ciências tem respondido a crises e a contingências políticas. Um exemplo emblemático foi o movimento de reforma educacional empreendido nos Estados Unidos, na década de 1950, quando os soviéticos obtiveram êxito no lançamento do Sputnik. O baixo desempenho dos estudantes norte-americanos nas disciplinas científicas foi considerado um fator importante dessa derrota. As medidas tomadas para enfrentar a crise voltaram-se para as melhorias do ensino das ciências por meio da chamada primeira geração dos projetos curriculares. Paralelamente, acrescentava-se a intenção de identificação de novas vocações científicas que viessem a formar uma elite responsável por alavancar o desenvolvimento científico e tecnológico, visto como estratégico naquele momento. Outros projetos curriculares para a melhoria do ensino de ciências, com diretrizes distintas, foram desenvolvidos em outros países, como no Reino Unido, com financiamento da Fundação Nuffield.

No Brasil, vários destes materiais produzidos no exterior foram traduzidos, em função da intensificação da valorização do ensino de Ciências que também se iniciou, no país, nos anos 1950, com apoio de órgãos públicos nacionais, internacionais e das sociedades científicas. A política de estado do fortalecimento do desenvolvimento científico e tecnológico correlacionou, assim como o governo norte-americano, "o desenvolvimento produtivo do país e a formação em ciências da população" (LOPES, 2004, p. 8). Desde então, vários financiamentos governamentais foram direcionados ao ensino de Ciências, como, por exemplo: o Programa de Expansão e Melhoria do Ensino Médio (anos 1970 e 1980), o Subprograma Educação para Ciência em 1983, que se estendeu até 1990, e o Programa Pró-Ciências, de 1995 a 2003, direcionado à capacitação de professores de Física, Química, Biologia e Matemática.

No final dos anos 1990, uma reforma educacional é iniciada, estabelecendo-se Diretrizes e Parâmetros Curriculares Nacionais (BRASIL, 1999). Em 2002, apesar da troca de governo, essas políticas têm continuidade, mas novas políticas são implementadas, como: o programa Pró Universidade (PROUNI), o programa Reestruturação e Expansão das Universidades Federais (REUNI), o Plano de Desenvolvimento da Educação (PDE), o Bolsa-família, e as olimpíadas para as escolas públicas. Todas essas políticas têm impacto sobre o ensino de Ciências dos diversos níveis, ainda que o atinjam em diferentes graus.

Apesar de todas essas ações e investimentos, tanto internacional quanto nacionalmente, a situação crítica do ensino de Ciências não parece ter sido superada, como aponta Fourez (2003), referindo-se ao contexto de todos os países industrializados. De um modo geral, os pesquisadores em ensino de Ciências apontam que não há, hoje, um ensino de Ciências adequado nem em termos das necessidades formativas dos cidadãos, do interesse dos alunos ou com relação à formação epistemológica. Para Lemke (2005), a educação em ciências tem sido impulsionada por interesses políticos voltados, prioritariamente, para a formação da força de trabalho técnica e cientificamente preparada, que, por isso, assume caráter propedêutico, afastando-se das necessidades cotidianas dos alunos. Furió et al. (2001), num estudo acerca das concepções dos professores sobre os objetivos da educação, já alertavam para um ensino de Ciências centrado na elaboração de conceitos, princípios e leis específicas das disciplinas, que desconsidera os anseios da sociedade atual e ignora outros aspectos importantes da formação dos estudantes. 
Neste trabalho iremos focalizar, dentre as políticas educacionais em vigência, o investimento público nas olimpíadas escolares, e, em particular, nas científicas, que são financiadas em conjunto pelas sociedades científicas e por órgãos públicos brasileiros, como uma das medidas de estado que pretensamente visam à melhoria do ensino de Ciências nas escolas públicas. A ideia é questionar o investimento público neste tipo de ação para o Ensino Médio, interrogando a competitividade enquanto mediação cultural fundamental das olimpíadas frente à formação do cidadão, à escola como reprodutora das diferenças sociais e à produção do fracasso da maior parte dos participantes.

\section{Olimpíadas escolares: uma prática pouco questionada}

As olimpíadas escolares têm sido praticadas por vários países. No Brasil, anualmente, organizam-se olimpíadas de Matemática e Língua portuguesa, para as escolas públicas, patrocinadas pelo governo federal desde 2006. Universidades e sociedades científicas também têm organizado e financiado olimpíadas escolares. Por exemplo, a "Olimpíada Brasileira de Física" vem sendo organizada pela Sociedade Brasileira de Física para todos os estudantes do Ensino Médio e estudantes da última série do Ensino Fundamental há mais de uma década. A Olimpíada Brasileira de Biologia encontra-se em sua sexta edição. A competição é voltada para estudantes que cursam ou já concluíram o Ensino Médio e conta com o apoio da Secretaria de Inclusão Social do Ministério da Ciência e Tecnologia (MCT). Quanto à Olimpíada Brasileira de Química, trata-se também de um evento anual para estudantes do Ensino Médio e tecnológico. Em 1986, por iniciativa do Instituto de Química da Universidade de São Paulo (USP), com o apoio da Fundação de Amparo à Pesquisa do Estado de São Paulo (FAPESP), da Secretaria da Ciência e Tecnologia do Estado de São Paulo e do Conselho Nacional de Desenvolvimento Científico e Tecnológico (CNPq), realizou-se o primeiro evento, com a participação de cinco estados brasileiros. Atualmente, recebe apoio do CNPq. A exemplo das de Língua portuguesa e de Matemática, provavelmente, as olimpíadas das disciplinas científicas serão promovidas, muito em breve, pelo governo federal, para as escolas públicas.

No entanto, a reflexão acadêmica sobre as olimpíadas escolares é praticamente inexistente na literatura brasileira. Os poucos estudos encontrados se detêm na classificação e na análise das questões das provas aplicadas (ZÁRATE; CANALLE; SILVA, 2009) ou na resolução de questões (COLEONI; GANGOZO; HAMITY, 2001) utilizadas em olimpíadas.

Coleoni, Gangozo e Hamity (2001) analisaram resoluções escritas de um problema de física, por alunos de Ensino Médio, participantes de uma olimpíada. A partir de uma perspectiva cognitivista da pesquisa em educação científica, os autores apontam a dificuldade dos alunos de integrarem o formalismo específico da disciplina ao significado da situação proposta, ao categorizarem erros dos estudantes vinculados a deficiências nos mecanismos de controle da compreensão durante o processo de resolução. A pesquisa é desenvolvida de forma totalmente acrítica em relação ao tipo de problemas propostos, aos objetivos das olimpíadas no contexto da educação científica e em relação às condições socioculturais que distinguiriam alunos que conseguem ler e compreender os problemas daqueles que não conseguem. 
Rezende, F.; Ostermann, F.

Apenas um estudo (NASCIMENTO; PALHANO; OEIRAS, 2007) deteve-se nos objetivos educacionais e efeitos deste tipo de prática. Neste trabalho, que relata a participação de sete estudantes de um Centro Federal de Educação Tecnológica (CEFET) na olimpíada brasileira de informática, é interessante perceber o paralelo perfeito que os autores fazem com a competição esportiva, como se os objetivos de ambos fossem os mesmos:

Assim como modalidades esportivas, para se obter um bom resultado em uma competição de conhecimento é importante que haja a preparação do "atleta". Para que ocorra o estar junto do treinador (no caso, um professor) e os competidores (seus alunos), novamente são necessárias a organização e a disponibilidade de todos em termos de tempo e local para o treinamento, requisitos difíceis de serem atendidos [...]. (NASCIMENTO; PALHANO; OEIRAS, 2007, p. 285)

Os autores não problematizam este paralelo, assumindo, portanto, a competitividade como um valor a ser desenvolvido pela escola. Uma entrevista realizada com a professora da disciplina de Algoritmo e Linguagem de Programação revelou que, com exceção de um, os competidores eram os mais interessados da turma. O pequeno número de competidores apesar de os autores justificarem pelo pouco tempo para inscrições - pode mostrar quanto esse tipo de atividade produz exclusão na escola. A caracterização que a professora faz do grupo mostra que a participação já promove uma seleção mesmo antes da competição ser iniciada. Este aspecto não chama a atenção dos autores, que preferem ver quanto o único aluno não interessado, de início, na disciplina melhorou seu desempenho.

Outro dado preocupante foi o fato de nenhum dos alunos ter alcançado o número mínimo de pontos para aprovação para a segunda fase. Ao invés de esse dado levar os autores a uma reflexão mais profunda sobre a experiência dos alunos, eles insistem em considerar efeitos puramente positivos, como, por exemplo, no desenvolvimento de autonomia e maior interesse desses alunos pela disciplina.

\section{Competitividade, colaboração e aprendizagem}

As olimpíadas escolares de qualquer disciplina se espelham nas competições esportivas mundiais que visam à seleção de vencedores e, consequentemente, de perdedores nas diversas modalidades de esporte. Das competições esportivas, participam atletas treinados minuciosamente por anos a fio, com apoio de diferentes países e de empresas. No entanto, nos últimos anos, não precisamos assistir aos jogos e competições para antecipar o grupo de seis ou dez países de onde são recrutados os vencedores. Os países mais ricos têm, em geral, melhor desempenho que os mais pobres. O "talento" esportivo estaria, então, condicionado à origem socioeconômica do atleta.

O peso desigual do nível socioeconômico não é o único aspecto que pode nos levar a questionar as olimpíadas esportivas, mas outros são igualmente preocupantes, como por exemplo: os investimentos altíssimos em propagandas, a competição entre empresas que investem nos times e atletas individuais, os altíssimos lucros auferidos antes, durante e após os jogos, e 
o "espírito de competição" vivenciado pelos atletas e por todo o público. Por mais que a cerimônia de abertura nos leve a imaginar um cenário de paz e de confraternização entre todos os países, sabemos que, a partir daquele momento, a lei é a da competição e o que vale é a luta pelas medalhas.

As olimpíadas científicas, por sua vez, são sustentadas pelos objetivos dos cientistas que buscam novos talentos para incrementar os quadros científicos do país. Este objetivo encontra ressonância na política desenvolvimentista do governo brasileiro dos últimos quarenta anos. Por outro lado, avanços na política educacional, com a promulgação da Lei de Diretrizes e Bases (LDB), apontam outros objetivos para a formação dos estudantes de nível médio, destacando-se o exercício pleno da cidadania - algo bem mais amplo que a formação técnica.

A mentalidade que defende as olimpíadas científicas parece pautar-se na ideia de que a construção do conhecimento científico baseia-se na contribuição de talentos individuais. Este aspecto está cada vez mais questionado nas narrativas epistemológicas contemporâneas que veem a construção da ciência como coletiva e distribuída. Também a aprendizagem é cada vez mais aceita como um processo eminentemente social. A perspectiva sociocultural vem enfatizando seu caráter mediado por outros indivíduos e pela linguagem. Isso não quer dizer que o indivíduo não se desenvolva ou possa aprender sozinho, mas que precisa de algum tipo de mediação, exercida por um material ou por outro indivíduo. Além de possibilitar aprendizagem efetiva, a interação e a colaboração são valores defensáveis tanto do ponto de vista cognitivo ou educativo quanto do ponto de vista da formação humana.

Seguindo a tradição da escola soviética de Vygotsky, Wertsch $(1988,1993)$ delineia seus pressupostos a partir da afirmação de que as funções mentais superiores no indivíduo derivam da vida social, e que a ação humana, tanto no plano individual como no social, é mediada por instrumentos e signos.

A ideia da aprendizagem social pode ser depreendida da lei genética geral de desenvolvimento cultural de Vygotsky (VYGOTSKY apud WERTSCH, 1988, p. 77):

Qualquer função presente no desenvolvimento cultural da criança aparece duas vezes ou em dois planos distintos: em primeiro lugar aparece no plano social, para em seguida, aparecer no plano psicológico. Em princípio, aparece entre as pessoas e como uma categoria interpsicológica, para em seguida aparecer na criança como uma categoria intrapsicológica. Isto é igualmente certo com respeito à atenção voluntária, à memória lógica, à formação de conceitos e ao desenvolvimento da volição. Podemos considerar esta argumentação como uma lei no sentido estrito do termo, ainda que a internalização transforme o processo em si mesmo, transformando sua estrutura e funções. As relações sociais ou relações entre as pessoas subjazem geneticamente a todas as funções superiores e a suas relações.

A lei geral de desenvolvimento cultural de Vygotsky por si só não direciona a formação, no sujeito, de um caráter competitivo ou colaborativo. Sendo dialeticamente consequente das relações sociais, o desenvolvimento pode resultar em indivíduos diferenciados, de acordo 
com diferentes contextos socioculturais. Entretanto, com o conceito de zona de desenvolvimento proximal, que expande a lei genética geral de desenvolvimento cultural, Vygotsky dá uma direção para esta formação, enfatizando o papel da colaboração no desenvolvimento cognitivo e na aprendizagem. Trata-se de uma espécie de estágio dentro do qual uma criança ou um estudante, com o auxílio direto ou indireto de um adulto, podem desempenhar tarefas que, sozinhos, não fariam, por estarem acima do seu nível de desenvolvimento (VYGOTSKY apud WERTSCH, 1988).

Além de enfatizar o papel da colaboração no processo de aprendizagem, a proposta teórica de Vygotsky inverte a relação entre o aprendizado e o desenvolvimento: ao contrário de outras teorias pedagógicas, como a piagetiana, que sugerem a necessidade de o ensino ajustarse a estruturas mentais já estabelecidas, para Vygotsky, o aprendizado orientado para níveis de desenvolvimento que já foram atingidos é ineficaz do ponto de vista do desenvolvimento global do estudante. Ele não se dirige para um novo estágio do processo de desenvolvimento, mas, ao invés disso, vai a reboque desse processo (VYGOTSKY apud WERTSCH, 1988).

A escola, como motor do desenvolvimento, tem um papel importante nesta perspectiva. É destacada, portanto, a importância da figura do professor como identificação/modelo e como elemento-chave nas interações sociais do estudante. Trata-se, portanto, de um modelo que dá destaque ao caráter colaborativo da aprendizagem tipicamente humana, uma vez que as funções psicológicas superiores e conscientes (pensamento, linguagem, formação de conceitos, atenção voluntária) são de origem sociocultural. Os processos elementares (como os reflexos) são de origem biológica e constituem sua "pré-história".

Assim, na tradição vygotskyana, não há espaço para princípios educativos que sustentem a disseminação do espírito competitivo no contexto escolar. Portanto, é importante desconstruir argumentos que defendem o comportamento competitivo como sendo próprio da natureza humana. Não existe natureza humana dada, mas apenas modelos do que é ser humano. $\mathrm{O}$ argumento que justifica a competitividade como naturalmente humana é fruto da opção por um modelo, entre outros.

\section{Olimpíadas na escola reprodutora das diferenças sociais}

Até meados do século passado, predominava nas Ciências Sociais e no senso comum uma visão funcionalista em que, através da escolarização, seria possível construir uma sociedade justa (meritocrática), moderna (centrada na razão e nos conhecimentos científicos) e democrática (fundamentada na autonomia individual). A escola pública e gratuita resolveria o problema do acesso à educação, o que garantiria a igualdade de oportunidades entre os cidadãos: os indivíduos competiriam, em condições de igualdade, dentro do sistema de ensino. Aqueles que se destacassem por seus dons seriam justamente levados a avançar em carreiras escolares, ocupando, posteriormente, posições superiores na hierarquia social. Neste contexto, a escola seria uma instituição neutra, difusora do conhecimento racional e objetivo, que selecionaria os melhores a partir de critérios racionais.

Nos anos 1960, esta concepção de escola é abalada por uma profunda crise, o que irrompe numa releitura pessimista do papel dos sistemas de ensino na sociedade. Dois momentos podem ser considerados importantes nesta nova interpretação sobre a educação. $\mathrm{O}$ 
primeiro deu-se no final dos anos 1950, quando uma série de grandes pesquisas quantitativas patrocinadas pelos governos inglês, francês e norte-americano mostrou claramente a influência da origem social sobre o destino escolar. Os resultados não provocaram contestações imediatas acerca da perspectiva funcionalista, pois foram vistos como indicadores de problemas passageiros do sistema de ensino, que poderiam ser ajustados através de maiores investimentos. Mas, em médio prazo, desgastaram a propagada ideia acerca da igualdade de oportunidades resguardada pela escola. O segundo momento ocorreu nos anos 1960, quando a massificação do ensino gerou efeitos inesperados, como a frustração de se obter um certificado escolar de baixo retorno social e econômico no mercado de trabalho: a massificação do ensino e a desvalorização dos títulos escolares cessaram as expectativas de mobilidade social através da escola.

Uma nova interpretação da escola e da educação com base naqueles dados surgiu com Bourdieu e Passeron (1975), que apontaram a forte relação entre desempenho escolar e origem social, o que se tornou a sustentação de sua nova teoria. A perspectiva sobre a educação é totalmente invertida: ao invés de ser o local de transformação e democratização das sociedades, a instituição escolar (inclusive a universidade) passa a ser considerada como um dos principais lócus que contribui para a manutenção e a legitimação de privilégios sociais.

Por que defender a competição entre alunos ou entre escolas? Qual seria o princípio educativo que possibilitaria defender a disseminação do espírito competitivo? $\mathrm{Na}$ realidade, se pensarmos na escola tal como ela vem se desenvolvendo desde o século XVIII, a partir de seus laços íntimos com o sistema capitalista, as olimpíadas escolares parecem uma proposta educativa "coerente". Sabemos que a competição nunca esteve fora da escola, e do sistema educacional, defendida em nome da meritocracia. Sociólogos como Bourdieu e Passeron (1975), por exemplo, têm mostrado, no entanto, desde a década de 1970, que essa meritocracia tem raízes nas diferenças entre classes sociais e que, portanto, não pode ser vista apenas como uma ordenação por mérito. Neste sentido, é muito provável que as diferenças socioculturais entre as escolas que participam das olimpíadas desempenhem papel importante na seleção dos melhores.

Bourdieu e Passeron (1975) negam o caráter autônomo do sujeito individual e consideram a caracterização do indivíduo como relacionada à sua bagagem socialmente herdada, bagagem esta que inclui: o capital econômico e os bens e serviços a que ele dá acesso; o capital social, ou seja, o conjunto de relacionamentos sociais influentes mantidos pela família; o capital cultural, formado, sobretudo, por títulos de escolaridade.

A herança cultural familiar pode ser (e, normalmente, é) posta a serviço do sucesso escolar: para Bourdieu e Passeron (1975), o capital cultural é o elemento que tem o maior impacto no destino escolar dos sujeitos. Esse é um diferencial de sua teoria sobre educação: ressalta o fator cultural e atribui a este maior importância, em relação ao fator econômico, nas explicações sobre as desigualdades escolares. Para esses sociólogos, o capital cultural facilitaria a aprendizagem dos conteúdos e dos códigos veiculados pela escola, favorecendo o desempenho escolar daqueles cujo meio familiar compartilha dos mesmos valores.

As ideias de Dubet (2004) ajudam, também, a se refletir sobre a concepção puramente meritocrática da justiça escolar. Tal concepção defronta-se com grandes dificuldades, pois a sociologia da educação mostrou que a abertura de um espaço de competição escolar objetiva - tal como as olimpíadas - não elimina as desigualdades, já que as desigualdades sociais pesam muito nas desigualdades escolares. Os mais favorecidos têm vantagens decisivas. O modelo de 
igualdade de oportunidades implica sérios problemas pedagógicos. O princípio meritocrático pressupõe que todos os alunos que estejam envolvidos em testes escolares ou em competições escolares, como as olimpíadas, sejam submetidos, obviamente, às mesmas provas. É claro que as diferenças se aprofundam rapidamente, e alguns alunos parecem incapazes de continuar competindo. Dado o fracasso da maioria dos estudantes, a avaliação escolar cria enormes desigualdades entre alunos bons e os menos bons, o que é próprio de todas as competições escolares, tais como as olimpíadas.

Dubet (2004) também destaca uma certa "crueldade" do modelo meritocrático: quando adotamos o ideal da "competição justa e formalmente pura", os "vencidos", os alunos que fracassam, não são mais vistos como vítimas de uma injustiça social, e sim como responsáveis por seu fracasso, pois a escola lhes deu, a priori, todas as chances para terem sucesso como os outros. As olimpíadas escolares os atraíram para uma competição da qual foram excluídos de antemão; eles descobrem suas fraquezas, sem o consolo de poder atribuir o fato às desigualdades sociais. A crueldade estaria no fato de que a pretensa competição escolar justa reforça o sentimento de fracasso escolar, que passa a ser legítimo na visão dos estudantes.

\section{Encaminhamentos alternativos}

Os pontos levantados anteriormente levam ao questionamento das olimpíadas escolares e à defesa de projetos educacionais alternativos que se apoiem na mediação pedagógica e promovam a colaboração e a democracia no ambiente escolar. Uma ideia interessante pode ser buscar balanço entre competição e cooperação focando em grupos, e não em indivíduos, como propõe o projeto de olimpíada brasileira de ciências das escolas públicas, de autoria da Universidade Federal de Minas Gerais (UFMG), ainda não colocado em prática. Essa proposta também traz contribuições relevantes ao propor atividades distintas das provas tradicionais a serem desenvolvidas por equipes de estudantes, com orientação dos professores. O objetivo é que os desafios propostos aos estudantes possibilitem a apropriação de conhecimentos potencialmente relevantes para a vida na sociedade contemporânea e "favoreçam a construção de identidade e de pertencimento dos estudantes ao seu território e grupo social, em um contexto histórico e geográfico específico" (UNIVERSIDADE FEDERAL DE MINAS GERAIS, 2009, p. 12).

Outro ponto a ser considerado é o tipo de atitude que se pretende formar nos alunos em relação à ciência. A formação científica não pode se restringir a despertar o interesse pela ciência, mas precisa ter, como objetivo, promover o espírito crítico do indivíduo em relação ao empreendimento científico. Este objetivo não é contemplado com as olimpíadas científicas.

As olimpíadas escolares só podem ser aceitas como tapa-buraco, encobrindo as reais necessidades e as possibilidades de soluções sérias no âmbito do ensino de ciências. Dubet (2004) traz um encaminhamento possível para a questão da construção de uma escola mais justa, assumindo uma postura não radical e, ao mesmo tempo, pragmática, ao propor princípios de justiça que poderiam ser compatíveis com o modelo meritocrático.

Um dos aspectos defendidos pelo autor trata do princípio da discriminação positiva, no qual a escola, para ser mais justa, deve levar em conta as desigualdades reais, procurando, em certa medida, compensá-las. Estudos dirigidos, atividades esportivas e culturais, estabilida- 
de e qualidade das equipes educacionais, preparação específica para concursos e exames seriam formas de introduzir mecanismos compensatórios eficazes e centrados nos alunos e em seu trabalho. Em certos casos, é preciso ultrapassar a "igualdade pura", considerando-se, por exemplo, a necessidade de criação de quotas para garantirmos a participação de minorias em diferentes âmbitos na sociedade. Para que bons alunos de bairros periféricos possam realizar bons estudos é preciso oportunizar uma preparação específica, ou, se queremos diminuir o analfabetismo, precisamos lutar por uma carga horária mais extensa nas escolas. Há de se reconhecer, entretanto, que essas ações têm uma influência limitada e não conseguem alterar sensivelmente o jogo da produção das desigualdades escolares.

A garantia de um mínimo de proteção e recursos aos mais fracos e desfavorecidos é uma maneira de se fazer justiça social. Desse ponto de vista, um sistema justo deve garantir limites mínimos abaixo dos quais ninguém deveria ficar. Nesse modelo, a justiça de um sistema escolar poderia ser medida pelo modo como trata os mais fracos, e não somente quanto ela fomenta uma competição pura. As desigualdades são aceitáveis, ou mesmo justas, quando não pioram as condições dos mais fracos. O sistema escolar justo, ou menos injusto, não é o que reduz as desigualdades entre os melhores e os mais fracos, mas o que garante aquisições e competências vistas como elementares para os alunos mais fracos e desfavorecidos.

O reconhecimento de uma escola justa passa pelo fato de que ela trata bem os vencidos, não os fere, não os humilha, preservando sua dignidade e igualdade de princípios com os outros. Os vencidos serão mais bem tratados quando se pensar que a escola deve educar todos os alunos independentemente do seu desempenho escolar ou origem social, quando os alunos e suas famílias se associarem à vida da escola, quando os alunos forem tratados como sujeitos em evolução, e não apenas como alunos engajados em uma competição ou em uma olimpíada.

Apple e Beane (2001) relatam experiências de escolas democráticas, que tanto procuram criar estruturas e processos democráticos por meio dos quais a vida escolar se realize, como, também, um currículo que ofereça experiências democráticas aos jovens. As pessoas envolvidas com as escolas democráticas consideram-se participantes de comunidades de aprendizagem. Embora estas comunidades valorizem a diversidade, consideram o bem comum como característica da democracia e, por isso, "as comunidades de alunos das escolas democráticas são marcadas pela ênfase na cooperação e na colaboração, e não na competição" (APPLE e BEANE, 2001, p. 22). Assim, os jovens são encorajados a se interessarem pelos outros e a melhorarem a vida da comunidade ajudando os outros.

Embora o acesso à escola já seja visto como um aspecto necessário das escolas democráticas, também é importante que todos os jovens tenham direito a todos os programas da escola e a seus frutos de valores. Para tanto, é necessário que as escolas não coloquem barreiras institucionais aos jovens. São feitos "todos os esforços possíveis para eliminar a formação de grupos com base na capacidade dos alunos, provas preconceituosas e outras iniciativas que tantas vezes impedem o acesso à escola sob o pretexto de raça, sexo e classe socioeconômica" (APPLE e BEANE, 2001, p. 23).

Os educadores das escolas democráticas estão conscientes de que as fontes de desigualdade na escola têm origem na sociedade e, por isso, também estão preocupados em mudar as condições que as geram. Este interesse exige uma posição firme contra todos os tipos de desigualdade presentes na escola e na sociedade. $O$ trabalho na escola, a partir deste posicionamento, é exaustivo e conflituoso, sobretudo porque as "escolas têm sido instituições nota- 
Rezende, F.; Ostermann, F.

velmente antidemocráticas" (APPLE e BEANE, 2001, p. 24), contaminadas por estruturas, como formação de grupos com base na capacidade dos alunos, que negam oportunidades iguais a muitos, especialmente aos pobres, aos negros e às mulheres.

\section{Discussão e considerações finais}

Com base na discussão apresentada, questionamos a prática das olimpíadas escolares como uma das medidas de Estado que, pretensamente, visam à melhoria do ensino nas escolas públicas, e, mais fortemente, as olimpíadas das Ciências da Natureza, área de conhecimentos historicamente excludente. A partir da perspectiva histórico-cultural sobre aprendizagem, e com base na sociologia da educação, argumentamos contra a competitividade entre estudantes já pré-selecionados por seu capital cultural, e a favor da colaboração nos processos educativos. Defendemos que a interação, a colaboração e a democracia são valores defensáveis tanto do ponto de vista cognitivo ou educativo quanto do ponto de vista da formação humana. Avanços na política educacional brasileira, com a promulgação da $\mathrm{LDB}$, também apontam outros objetivos para a formação dos estudantes de nível médio, destacando-se o exercício pleno da cidadania - algo bem mais amplo do que a formação técnica ou a busca por novas vocações científicas.

Caminhos alternativos podem ser buscados visando a um balanço entre competição e cooperação focando em grupos, e não em indivíduos. A construção de uma escola mais justa (no contexto educacional francês), por exemplo, pode passar por uma postura não radical e, ao mesmo tempo, pragmática, propondo-se princípios de justiça que poderiam ser compatíveis com o modelo meritocrático. Este projeto talvez fosse compatível com o que propõe o projeto de olimpíada brasileira de ciências das escolas públicas de autoria da UFMG, ainda não colocado em prática. Experiências mais radicais, como a proposta das escolas democráticas (no contexto norte-americano), em que as pessoas consideram-se participantes de comunidades de aprendizagem, representam uma direção promissora na valorização da diversidade, da cooperação e da colaboração, e não na competição. Neste contexto, não faria sentido a proposta de olimpíadas escolares, mesmo que se balizasse pela competição entre grupos.

No Brasil, dada a desigualdade na realidade escolar e a falta de qualidade do ensino público, talvez um argumento a favor das olimpíadas escolares fosse o de que é melhor implementar um projeto como o das olimpíadas, apesar de críticas que possam se fazer a esta prática, do que não ofertar nada. Entretanto, esse argumento é perverso. Passada a mobilização que o evento possa causar nas escolas, pode-se perguntar: o que fica dessa experiência? Que valores foram levados aos alunos? Como passaram a ver a realidade? Em que medida um evento como as olimpíadas os ajuda a ver a sua realidade criticamente? Que relação foi construída entre o conhecimento, a linguagem científica e as situações reais do cotidiano, de determinada cultura, sociedade, arte, artefatos? Que repertórios foram construídos? Será que teríamos de assumir, como valor a ser cultivado, apenas a formação do espírito competitivo, necessário à competição que o aluno irá encontrar no mercado de trabalho?

As olimpíadas funcionam da mesma forma que os exames oficiais, na medida em que os aprovados coincidem, na sua maioria, com o grupo que teve oportunidade de frequentar as melhores escolas e receberam maior capital cultural da família. 
Olimpíadas de Ciências: uma prática ...

Neste trabalho não nos dedicamos a explorar o fracasso da maioria dos estudantes nas olimpíadas científicas, mas este é um objeto que precisa ser pesquisado. O que significa o fracasso nas olimpíadas, situação mais frequente, que atinge a grande maioria, na formação da identidade do aluno que fracassa? O que sobra para os estudantes que não passam para as fases seguintes? Ou ainda, para os que não conseguem resolver nenhuma questão do teste? Qual o impacto deste fracasso na relação que ele irá estabelecer com as Ciências da Natureza? Tomar as olimpíadas como objeto de estudo envolve também buscar as histórias de vida da maioria de fracassados que ela promove, e não apenas dar visibilidade à parte da escola, dos professores e alunos que se mobilizaram para essa atividade. O que os excluídos dessa competição estão fazendo enquanto a escola treina seus melhores alunos para as provas? Ficam em casa sem aulas de Ciências, pois seus professores estão em treinamento?

Estas e outras questões precisam ser colocadas para as instituições governamentais que vêm promovendo as olimpíadas escolares, no sentido de se discutir amplamente esta prática que vem sendo tomada como garantia de se alcançar a qualidade da educação pública.

\section{Referências}

APPLE, M.; BEANE, J. O argumento por escolas democráticas. In M. APPLE; J. BEANE (Orgs.) Escolas Democráticas. São Paulo: Cortez Editora, 2001.

BANET, E. Finalidades de la educación científica en secundaria: opinión del profesorado sobre la situación actual. Enseñanza de las Ciencias, Barcelona, v. 25, n. 1, p. 5-20, 2007.

BOURDIEU, P.; PASSERON, J. C. A reprodução. Rio de Janeiro: Francisco Alves, 1975.

BRASIL. Ministério da Educação. Parâmetros curriculares nacionais: Ensino Médio. Brasília: Secretaria de Educação Média e Tecnológica, 1999.

COLEONI, E. A.; GANGOZO, Z. E.; HAMITY, V. H. La construcción de la representación en la resolución de un problema de física. Investigações em Ensino de Ciências, Porto Alegre, v. 6, n. 3, p. 285-298, 2001.

DUBET, F. O que é uma escola justa? Cadernos de Pesquisa, São Paulo, v. 34, n. 123, p. 539-555, set-dez, 2004.

FOUREZ, G. Crise no ensino de ciências? Investigações em Ensino de Ciências, Porto Alegre, v. 8, n. 2, p. 109-123, 2003.

FURIÓ, C. et al. Finalidades de la enseñanza de las ciencias en la secundaria obligatoria. ¿Alfabetización científica o preparación propedéutica? Enseñanza de las Ciencias, Barcelona, v. 19, n. 3, p. 365-376, 2001.

LEMKE, J. L. Research for the future of science education: new ways of learning, new ways of living. In: INTERNATIONAL CONGRESS ON RESEARCH IN SCIENCE TEACHING, 7., 2005, Granada. Anais... Granada: [s. n.], 2005. 
Rezende, F.; Ostermann, F.

LOPES, A C. Políticas de currículo: mediação por grupos disciplinares de ensino de ciências e matemática. In: LOPES, A. C.; MACEDO, E. (Org.). Currículo de ciências em debate. Campinas, SP: Papirus, 2004. p. 45-75.

NASCIMENTO, M. G. do; PALHANO, D.; OEIRAS, J. K. K. Competições escolares: uma alternativa na busca pela qualidade em educação. In: SIMPÓSIO BRASILEIRO DE

INFORMÁTICA NA EDUCAÇÃO, 18., 2007, São Paulo. Anais... São Paulo: [s. n.], 2007. p. 284-287.

UNIVERSIDADE FEDERAL DE MINAS GERAIS. Projeto da Olimpíada Brasileira de Ciências das escolas públicas. Belo Horizonte: UFMG; Faculdade de Educação, 2009. (Mimeo).

WERTSCH, J. Vygotsky y la formación social de la mente. Barcelona: Paidós, 1988.

. Voces de la mente - un enfoque sociocultural para el estúdio de la acción mediada. Madrid: Visor, 1993.

ZÁRATE, J. D. B.; CANALLE, J. B. G.; SILVA, J. M. N. da. Análise e classificação das questões das dez primeiras olimpíadas brasileiras de Astronomia e astronáutica. Caderno Brasileiro de Ensino de Física, Florianópolis, v. 26, n. 3, p. 609-624, dez. 2009.

Artigo recebido em 09/02/2011. Aceito em 08/10/2011. 